merely a collection of these spheres in a very high state of condensation. To illustrate this tendency to condense, the author compares it with the tendency of the sun and stars to cool and contract, and eventually co form bodies like the moon. This theory of the constitution of matter, we are told, explains all the natural phenomena of light, heat, electricity and magnetism, without a single contradiction.

Having tried to upset the existing theories, and having told us that this new theory will explain practically everything, the author, to our surprise, fails completely to put forward convincing proofs in support of its application to electricity and magnetism. A good example of the class of explanation with which the pamphlet abounds is to $x$ e found on page 48 , where the loss of electricity from conductors in damp weather is alluded to. A positively charged body is supposed to be surrounded by layers of negative ether spheres-that is, by spheres having a larger radius than the mean ether sphere. These negative ether spheres are in a high state of tension, and when a water molecule comes into the space which they occupy it relieves this tension, and so partly discharges the conductor. If we accept this explanation, there is absolutely nothing to prevent us supposing that small particles could discharge a conductor without touching it, or without being connected to it by any other material except the ether, as the author supposes that the layers of negative ether spheres, above alluded to, extend to finite distances from the conductor.

Experience, howeve 1 , will not allow us to accept such an explanation at all for it has been perfectly well established that the vapour rising from an electrified surface carries with it no charge. In connection with the magnetism of the earth we find, on page 90 , an interesting piece of information. We are there told that it is only those heavenly bodies which rotate that have polarity, and that, consequently, the moon is non-magnetic!

It is consoling to learn that the author has suffered hitherto so much from hostile critics that he can no longer be stung by the suggestion that his philosophy is "blank Unsinn."

J. S. T.

Farm and Garden Insects. By Prof. Wm. Somerville.

Pp. viii + I27. (London : Macmillan and Co., Ltd., I 897.)

A USEFUL little text-book for beginners, and an excellent reference book for practical farmers. The three parts into which the book is divided are judiciously arranged. The first gives in a clear and distinct manner the rudiments of entomology, and forms, therefore, a useful introduction to the second part, which describes some of the most common insect pests whose ravages cause so much loss to the farmer and gardener. This loss may be very much modified if the simple precautions and remedies contained in the book are adopted. The zppendix in a few pages gives most useful information about mites, ticks, \&c. ; not true insects certainly, but which, by attacking our domestic animals, and even man himself, cause an immense amount of irritation, intlammation, and consequent loss. Farmers, gardeners, and all interested in rural economy will do well to carefully study its pages.

Geology of North-east Durham. By D. Woolacott, B.Sc.

Pp. vi +84 . (Sunderland : Hills and Co., I897.)

THIS is an orderly account of the geological characteristics and history of North-east Durham. It is written in language easily understood by readers unacquainted with the elements of geological science, and will, therefore, interest a popular public as well as the student of British geology. The diagrams are very coarse ; but this is doubtless due to the fact that they were prepared for publication in a weekly newspaper, in which the articles now reprinted originally appeared.

NO. I 435 , VOL. 55$]$
LETTERS TO THE EDITOR.

[The Editor does not hold himself responsible for opinions ex. pressed by his correspondents. Neither can he undertake to return, or to correspond with the weriters of, rejectert manuscripts intended for this or uny other part of N ITURE. No notice is taken of anonymous communications.]

\section{Rate of Racial Change that accompanies Different Degrees of Severity in Selectiun.}

IT is well known, in a general way, that better results are obtained by breeding from very select specimens than from the less select; but the statement deserves to be expressed with greater precision. I will do so here, on the lines laid down in "Natural Inheritance" (Macmillan, I889), using the constant. there determined for the stature of British men, including amung them the coefficient by which female stature may be corrected to its equivalent male value, and thereby eliminating all trouble due to sexual differences.

On this basis, it will be shown, by way of illustrating a general problem, how much the stature of a breed of British men would be raised in each successive generation, under different specified degrees of severity in selection; also the utmost limits of stature to which they could be raised in the several cases, no change of type being supposed to occur in the interim.

Degrees of severity in selection admit of being defined by the method of ientiles (or percentiles) fully described in the above book. No ambiguity need arise in interpreting such a statement, as that a man occupies the ninetieth centesimal grade in stature among a population whose mean stature is 68.5 inches, and whose individual statures are normally distributed about that mean with a quartile of $1{ }^{\circ} 5$ inches. Referring to Table 8 in the book, it is seen that the normal deviation at 90 in a series whose quartile is $\mathbf{I}$, is $\mathbf{I} \cdot 90$; therefore, in the above case, its value is $I^{\circ} 9 \times \mathrm{I}^{\circ} 7$ inches $=3.23$ inches. The mean stature of the population is 68.50 inches, which has to be added to this, making a total of $7 \mathrm{r} 73$ inches. Consequently when it is said that those persons are selected for parents who occupy the grade of $90^{\circ}$ in their respective series, the degree of severity in the selection has been strictly defined. Similarly in respect to any other grade, such as $80^{\circ}$ or $70^{\circ}$. This method of defining severity of selection is applicable to every measurable character, and to every form of distribution, skew or other, revealed by observation.

The principle has been fully explained in the above book, by which successive generations of the same population are able to maintain the same statistical peculiarities notwithstanding the "scatter" of families. It was shown that the sons of parents of similar statures form a co-fraternity, whose mean is more mediocre than the parental statures. In other words, the mean of the co-fraternity regresses towards the mean of the race, the coefficient of regression in stature being $2 / 3$. Thus the children of parents of grade $90^{\circ}$ in stature, deviate on the average no more than $2 / 3 \times 3.23$ inches, or $2 \cdot 15$ inches, above the mean of the race. So much for the first generation of the selected parents.

In the second and subsequent generations, the "scatter" of the co-fraternities has to be considered. The quartile of every one of them was shown in the book to be $x \cdot 5$ inches, consequently the individuals who occupy the grade $90^{\circ}$ in a cofraternity, are $\mathrm{I}^{\cdot} 5 \times \mathrm{I} \cdot 90$, or 2.85 inches taller than the mean of the co-fraternity, which itself is $2 \cdot{ }_{5}$ inches above the mean of this race, making a total of $5^{\circ} \mathrm{O}$ inches. The mean of their offspring, that is of the individuals forming the second generation of the selected series, is $2 / 3$ of $5^{.00}$ inches, or 3.33 above the mean of the rest of the race.

These results are easily generalised and thrown into a formula, as follows : $w=$ coefficient of regression; $t=$ tabular deviation at the specified grade; $q=$ quartile of race ; $q^{\prime}=$ quartile of co. fraternity; $\alpha=t_{q} ; \beta=t q^{\prime}$. Then the mean deviation of the pedigree stock from the mean of the race, in each successive generation, is :-

Ist generation, wa.

and, w $w^{\prime}(w a+\beta)$

$n$th $\quad, \quad w^{n} \alpha+\frac{w-w}{\mathrm{I}-w} \beta$.

When $n$ is large, $w^{n}$ disappears and the limiting velue becomes $\frac{w}{I-w^{\beta}}$. If $w=\frac{2}{3}$ as above, the limiting value is equal to $2 \beta$. 